\title{
SILAT SELECTS RUSSULA TO ENGINEER AND SUPPLY A 700,000 TPY STEEL PLANT*
}

Alexandre Rizek Schultz ${ }^{1}$

\begin{abstract}
Silat, Siderúrgica Latino-americana, selected Russula as the main engineering contractor for their 700,000 tpy Greenfield steel plant dedicated to long and flat steel production. The project is currently under construction in the district Guararu in Caucaia in the metropolitan region of Fortaleza. The project will be developed in two phases. First phase: 600,000 tons per year rebar mill and 60,000 tpy steel mesh line; Second phase: 700,000 tpy melt shop ( 90 ton/hr EAF and 4 strand continuous caster for billets up to $180 \mathrm{~mm} \times 180 \mathrm{~mm}$ ).

Keywords: Silat; Siderúrgica latino-americana; Selected Russula as the main engineering contractor for their 700,000 tpy Greenfield steel plant.
\end{abstract}




\section{INTRODUÇÃO}

The project is currently under construction in the district Guararu in Caucaia in the metropolitan region of Fortaleza. The project will be developed in two phases.

First phase: 600,000 tons per year rebar and wire rod mill and 60,000 tpy steel mesh line.

Second phase: 700,000 tpy melt shop (90 ton/hr EAF and 4 strand continuous caster for billets up to $180 \mathrm{~mm} \times 180 \mathrm{~mm}$ ).

When complete, the project will span 148 hectare area, located at KM 32 of the BR222 highway in the town of Primavera in Caucaia, within the Pecém industrial port complex (CIPP), $50 \mathrm{~km}$ from the northern Brazilian city Fortaleza.

Founded in 2011, Silat (Siderúrgica Latino-americana) is a privately held Brazilian corporation, whose majority shareholder is the Hierros Añon Group of La Coruña, Spain. The total investment in the first implementation phase will be $\$ 300$ million and will create 200 direct jobs and 800 indirect jobs in the region.

As a minority shareholder, the Economic Development Agency of the State of Ceará (Adece), owns a $10 \%$ stake in the company.

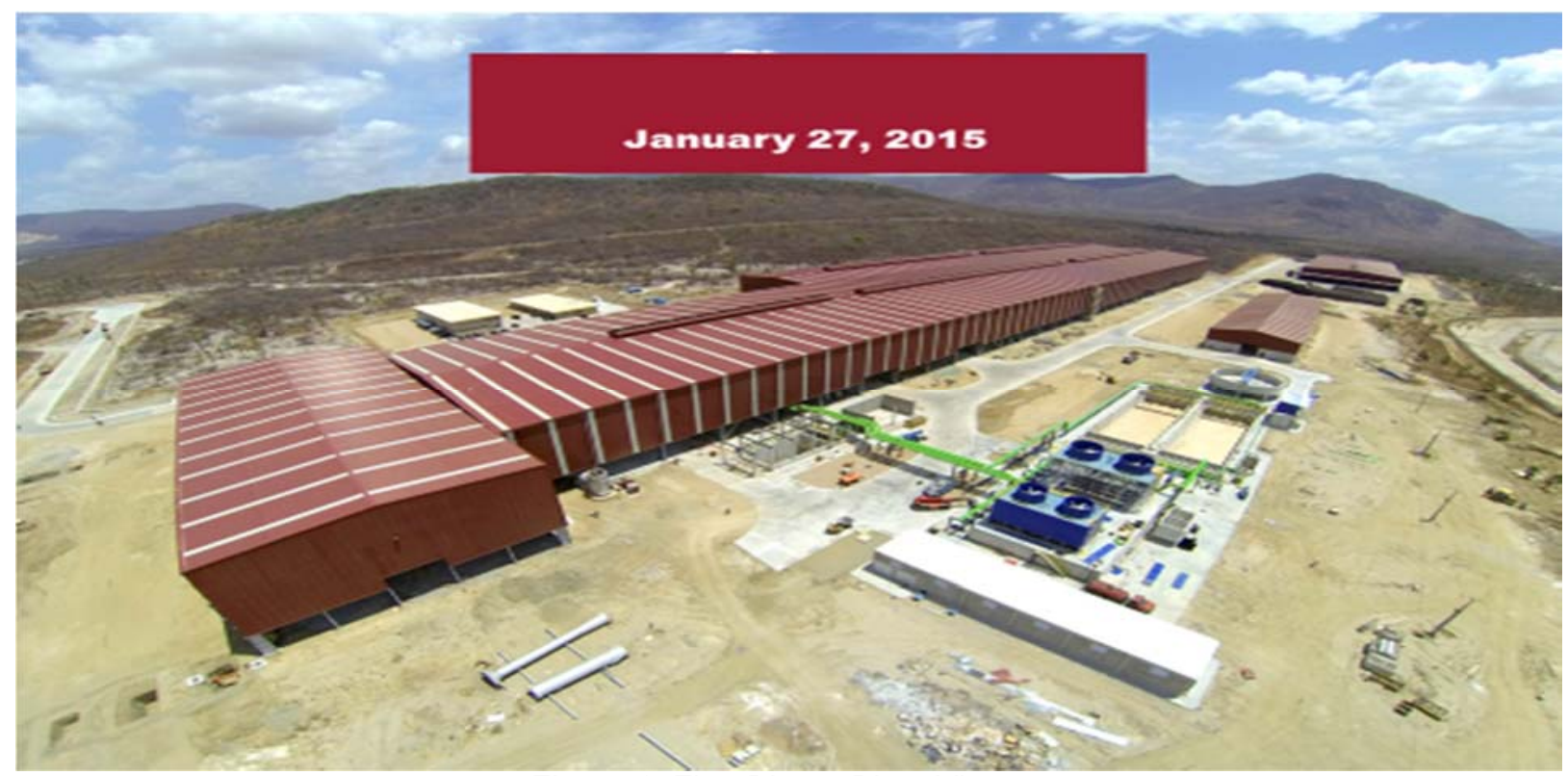

Figure 1: First Phase Plant View.

\section{PROJECT DESCRIPTION}

The project's first phase, construction of the steel mesh plant and bar and rod mill, will be completed in 2015. The product size range will include $8 \mathrm{~mm}$ to $32 \mathrm{~mm}$ bars, 5.5 to $16 \mathrm{~mm}$ wire rod in coil weighing up to $2.4 \mathrm{t}$ and $6 \mathrm{~mm}$ to $16 \mathrm{~mm}$ rebar in coils. The 60,000 tpy steel mesh plant is near construction completion and scheduled to start-up in the first quarter of this year.

The rolling mill will be capable of producing up to 600,000 tons of steel reinforcing bar and wire rod product annually. Starting material will be $130 \mathrm{~mm} \times 130 \mathrm{~mm}$ x $12,000 \mathrm{~mm}$ length billets weighing up to $1600 \mathrm{~kg}$ and $160 \mathrm{~mm} \times 160 \mathrm{~mm} \times 12,000$ $\mathrm{mm}$ length billets weighing up to $2,400 \mathrm{~kg}$.

The project's second phase will include a melt shop, which will produce 700,000 tpy billets annually, the raw material for the rolling of the long product steel. 
The cooperation between Russula and the Hierros Añon Group started in 1999 when Russula was contracted as the main engineering supplier of a 4 slit rolling mill that produced $8 \mathrm{~mm}$ to $32 \mathrm{~mm}$ rebar in Laracha, Spain. Originally designed to produce 350,000 tpy, the mill after installation had sustained production of 538,0000 tpy.

Several installations have been made since then, including the installation of a high speed wire rod mill producing 500,000 tpy $6 \mathrm{~mm}$ to $16 \mathrm{~mm}$ rebar in coils and $5.5 \mathrm{~mm}$ to $22 \mathrm{~mm}$ coils at the same site as the bar mill and continuing modernization projects.

\subsection{Rolling Mill Layout}

Russula has received an order from Silat to design, manufacture, install and commissioning a Rod and Bar Mill. The greenfield project will be carried out as a turnkey contract in two phases. The bar mill that has been designed to roll reinforcing bars from $8 \mathrm{~mm}$ to $32 \mathrm{~mm}$ with a slitting scheme and the option for quenching and tempering. Phase1 bar mill hot commissioning is scheduled for September 2014.

The second phase includes the installation of a rod outlet that has been designed to roll wire rod from $5.5 \mathrm{~mm}$ to $16 \mathrm{~mm}$ and reinforcing bars from $6 \mathrm{~mm}$ to $16 \mathrm{~mm}$. Phase 2 rod outlet hot commissioning is scheduled for January 2015.

The rolling mill will be fed by a 90 tph walking hearth reheating furnace.

The plant layout includes a 20-stand continuous mill with two outlets, one for straight bar and the other for wire rod in coil. The rod outlet includes a one 10-stand, highspeed twist free finishing block fed from the bar mill finishing stands.

The smaller bar sizes will be produced on four strands at very high speeds, to take advantage of the mill's capacity for the entire product range.

The experience that the personnel from SILAT gained at the operation of Siderúrgica Añón in Laracha, Spain were used as the basis for theprocess design and equipment selection. The objective was then to build a mill that would have low yield losses, high utilization and low conversion cost.

\subsection{Design Philosophy}

1) Proven Design Concepts for the mill layout, mechanical and electrical equipment;

a) Minimize initial investment and construction time;

b) Minimize commissioning time;

c) Source the equipment from reputable manufacturers to minimize uncertainty in the short and long run;

d) Minimize the amount of spares needed;

e) Easy to operate and maintain since personnel does not have any previous rolling experience;

f) Minimize yield losses and conversion costs.

2) Advanced Rolling Automation

a) The rolling recipes are easy to start up and maintain in order to maximize utilization.

b) The mill will run with a minimum amount of people so good automation is paramount. 


\subsection{Equipment Selection}

\section{1) Charging Table}

The charging table for the reheat furnace is designed for future hot charging when the new melt shop is commissioned.

\section{2) Walking Hearth Furnace}

A 90 tph walking hearth furnace with 24 meters between centers of the charging and discharging conveyors is included. Lateral doors to minimize heat losses and scale formation. Minimizes the use of water and easy to empty if not rolling 24/7.

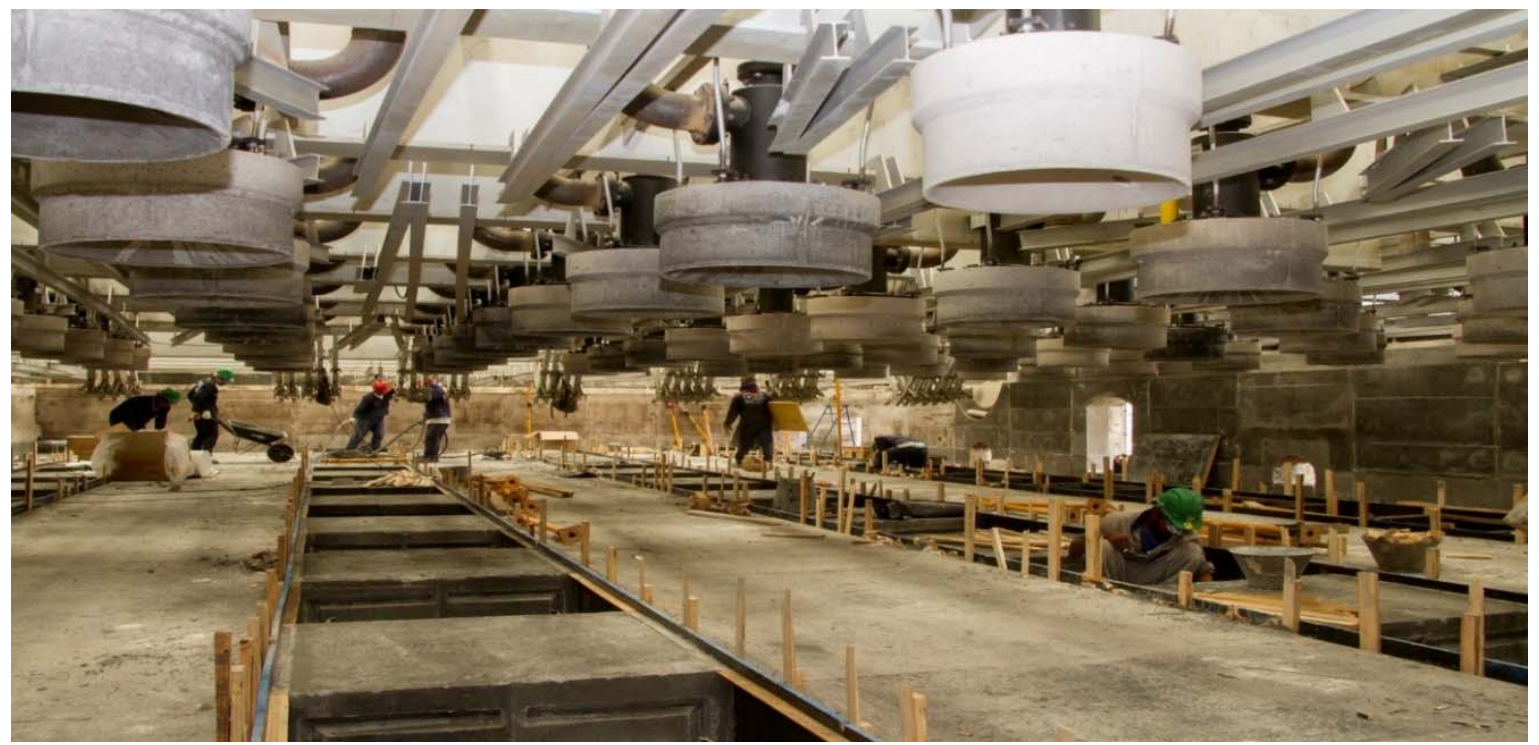

Figure 2: Internal view of the Billet Reheat Furnace during construction.

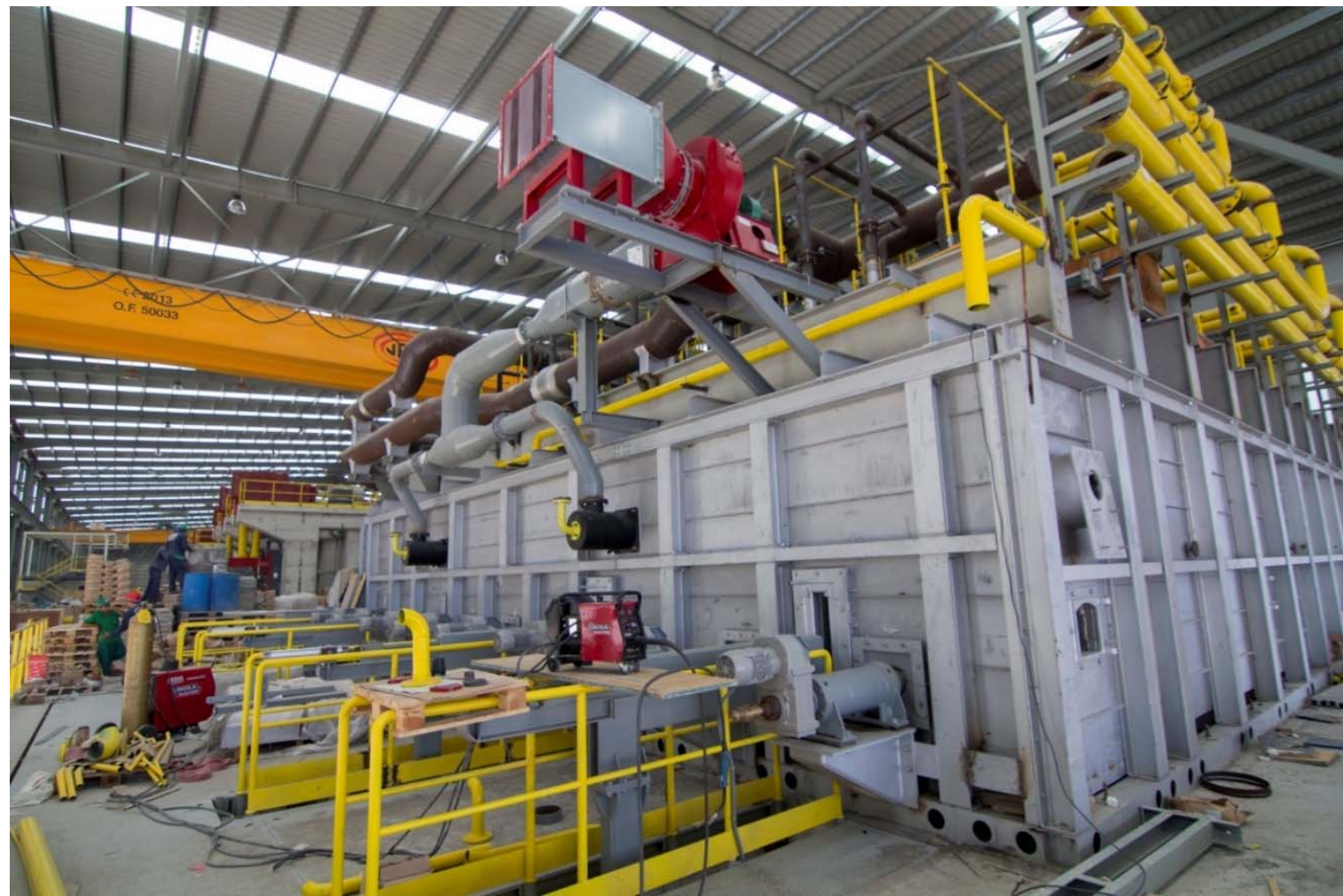

Figure 3: Billet Reheat Furnace 


\section{3) 20 Stand Bar Mill:}

In order to have a stable process the passes need to make reductions that are in line with their shape and purpose. Too much reduction is maintenance intensive while low reductions tend to lose control of the bar. Housingless stands are chosen to maximize mill utilization for long campaigns. To simplify operations only two roll neck sizes are used; 280 and $200 \mathrm{~mm}$ and two new roll diameters for each roll neck size.

This will minimize the number of spares needed for the stands without affecting the amount of reduction made by each pass. The stands at the roughing mill come with the guides mounted on the rest bars from the roll shop while the intermediate and finishing stands have the guides mounted on pedestals to minimize the time needed for pass changes. This feature also improves alignment accuracy.

The mill will be able to produce the whole product range with billets from $130 \times 130$ $\mathrm{mm}$ to $160 \times 160 \mathrm{~mm}$. This provides flexibility during the first months of operation since the new melt shop will be built after the mill is commissioned.

The pass sequence has been designed with a single pass line in the roughing and early intermediate mills to maximize efficiency.

The crop shears are located after stands 6 and 14. All the shears are start-stop to maximize accuracy and simplify maintenance. The shear after stand 14 is also used for optimization.

The divide shear after stand 20 can operate in rotary and crank modes depending on the speeds of the product being rolled.

The minimum tension control system will operate for stands 1 to 14 while the finishing mill will operate with uploopers in order to minimize yield losses and give stability to the rolling process. Since $8,10,12$ and $16 \mathrm{~mm}$ rebars will be rolled with a slitting pass design the last four stands are horizontal and special loopers and guiding equipment have to be used on the finishing mill and quenching zone. The rest of the mill is in a Horizontal - Vertical sequence to eliminate the need for twisting guides.

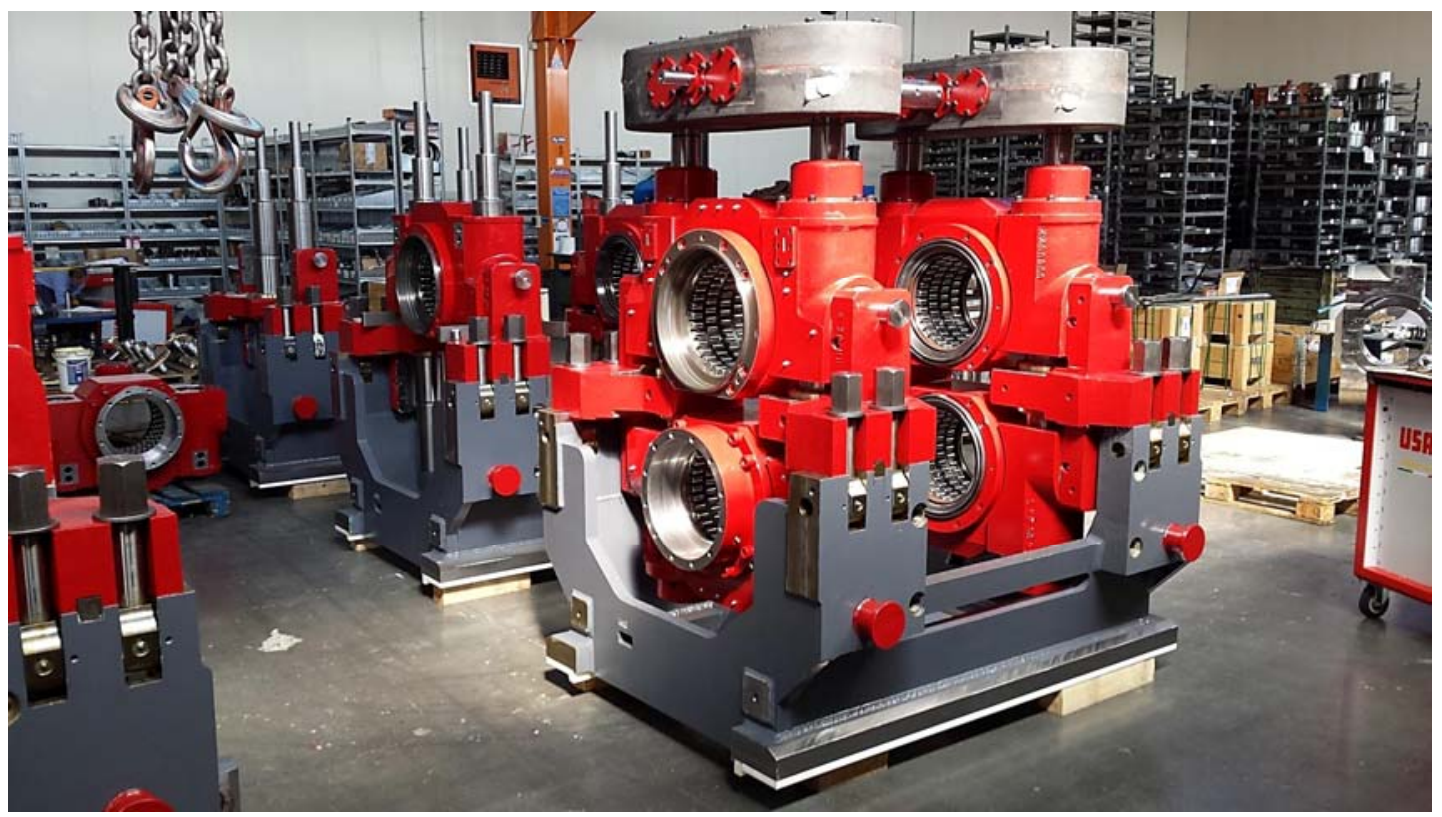

Figure 4: Housingless Rolling Stands

\section{4) Finishing Area}

Rebar quenching system in order to minimize the finished goods cash cost by reducing the carbon equivalent needed to achieve the standard mechanical properties. 


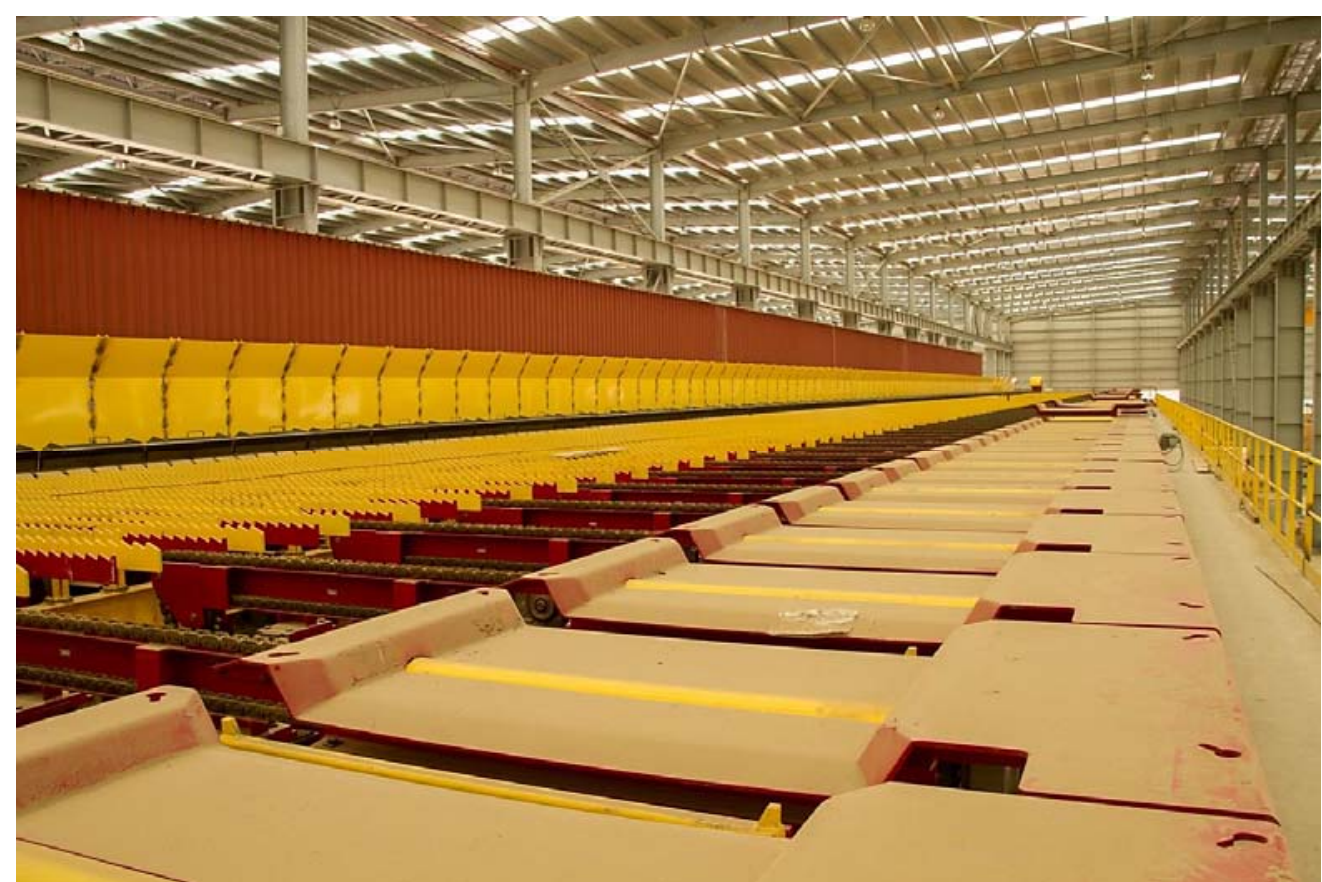

Figure 5: Coolilng Bed and its Exit Roller Table

\section{5) Cooling bed}

$102 \times 8$ meter cooling bed minimizes yield losses by reducing the number of cold shear crops per ton rolled.

\section{6) Cold shear}

The reciprocating cold shear has a nominal capacity of 650 tons and its blades are $1200 \mathrm{~mm}$ wide. Since the shear cuts the bars when they are stopped length accuracy is ensured. This will also minimize the length of the front and tail end crops.

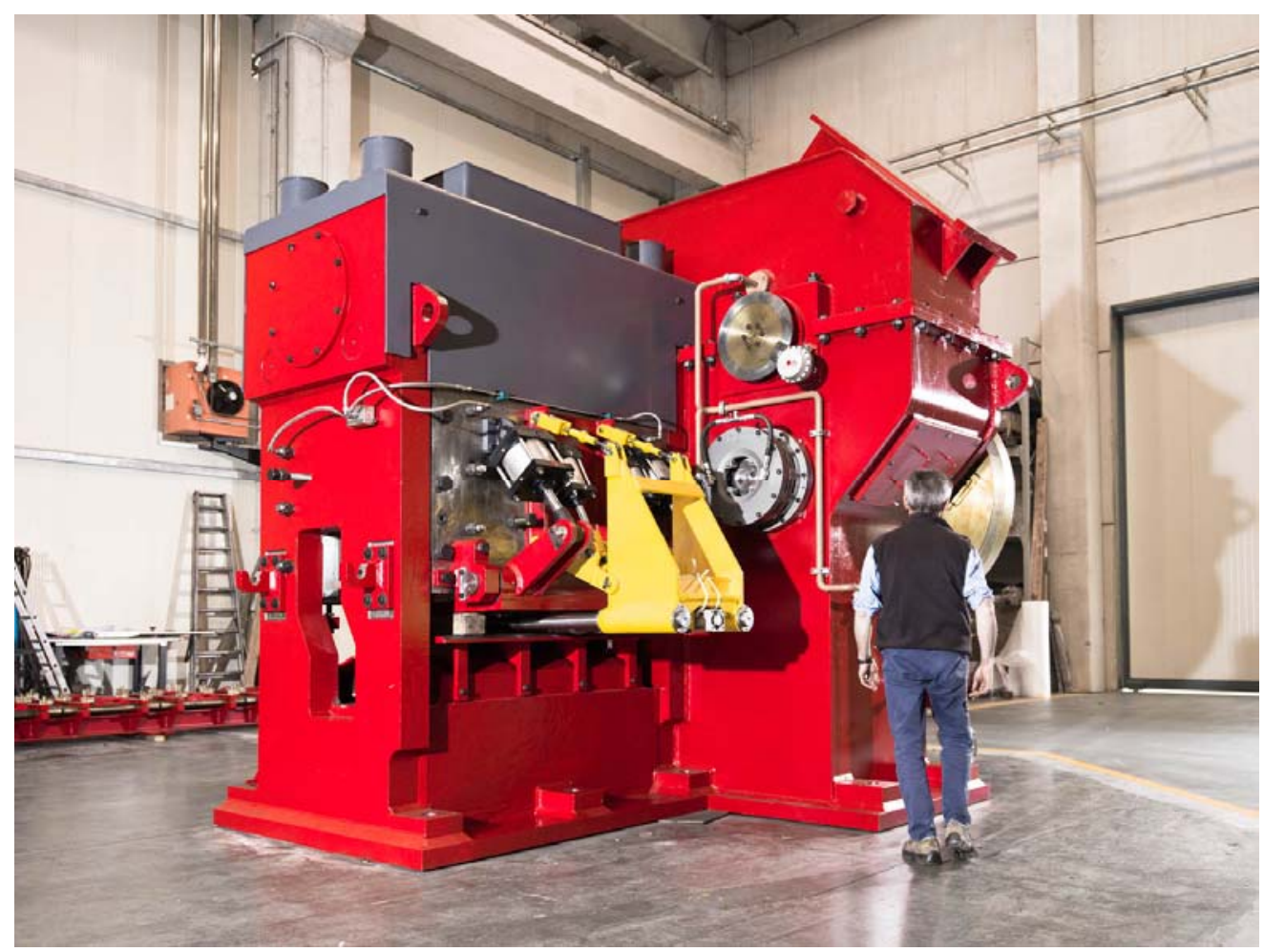

Figure 6: Cold Shear 


\section{7) Bundle forming and tying area}

Includes bar counting device and weighing and tagging station. Wire ties are the best solution for round bundles and minimize the tying cost. Initially the bundling station will consist of two 6 meters long sections with the option to add a third 6 meters long section in the future if 18 meters long products are requested by the market.

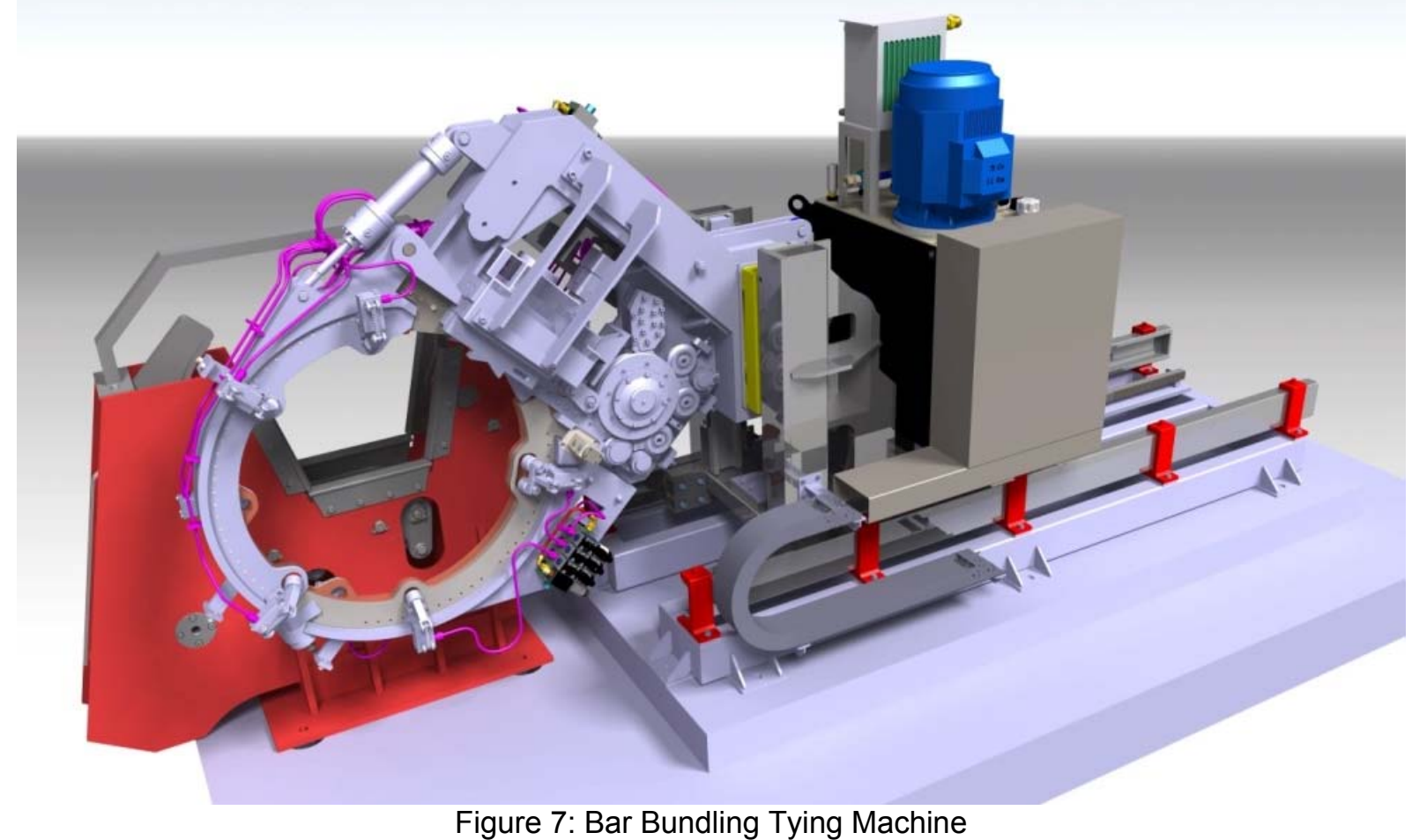

\section{8) Finishing block}

Wire rod and coiled rebar finishing block. Designed for low and medium carbon products.

\section{9) C-hook coil conveyor}

Coil forming station, pallet conveyor, hook conveyor, coil compacting and tying machine, coil weighing and tagging station and finally coil unloading table. Designed to keep up with the maximum throughput and produce coils as short as possible for each product. 


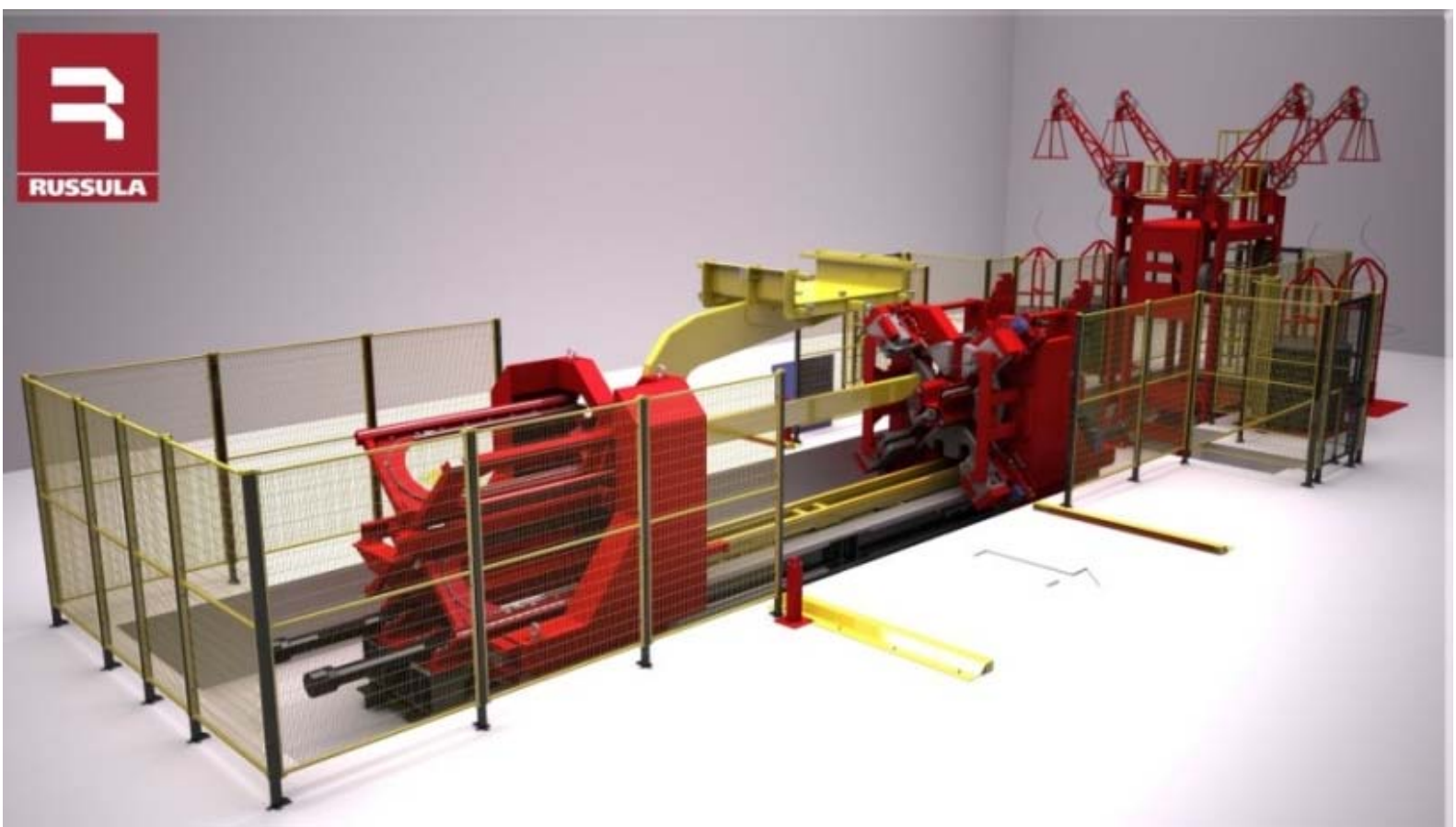

Figure 8: Coil Compactor

\section{0) Water treatment plant}

Contact water $2000 \mathrm{~m}_{3} / \mathrm{hr}$ and non-contact water $850 \mathrm{~m}_{3} / \mathrm{hr}$. Includes:
a) Scale pit
b) Dual decanting basins
c) Oil skimmer
d) Sludge thickening
e) Press plate filter
f) Ring filtration station
g) Cooling towers

\section{CONCLUSION}

The Steel Mesh Line is now in production and the Bar Mill is at start-up phase.

Time, cost and quality targets were met via focusing in the efficiency of the construction process. Prefabrication of piping as well as the integration of multiple engineering disciplines into the construction resulted in faster construction time, less labor and reduced material costs. 